\title{
Multisensory learning environments. Research project Education on Screen
}

\section{Les environnements d'apprentissage multisensoriels. Le projet de recherche "L'éducation sur l'écran»}

\author{
Aleksandr Fadeev and Alexandra Milyakina \\ Department of Semiotics, University of Tartu, Jakobi 2, 51005 Tartu, Estonia
}

\begin{abstract}
The unity of heterogeneous sensory channels plays an essential role in our learning and development. The multisensory approaches to learning imply a simultaneous use of visual, auditory, kinesthetic-tactile and other possible modalities. The paper analyses the affordances of multisensory learning via the framework of semiotics of culture and contemporary research in education, as well as explores the relations between multisensory perception of environment and multimodality of representation in learning. The multimodal nature of human communication became explicit in the age of the Internet and audiovisual media. The development of digital technology also made it possible to consider the multiplicity of representational modes in learning. Whereas multisensory learning practices usually emerge in vernacular contexts, the recent developments in education and semiotics of culture offer unprecedented means for supporting such practices both in formal and non-formal education. Also, the multisensory learning practices are inherent to the development of the new literacies necessary for meaning-making in the contemporary media environment. The theoretical discussion is followed by the analysis of a practical example - digital educational platform Education on Screen. The platform aims to facilitate a meaningful dialogue with the cultural heritage by means of multimodal and multisensory learning.
\end{abstract}

Résumé. L'unité de canaux sensoriels hétérogènes joue un rôle essentiel dans notre apprentissage et développement. Les approches multisensorielles à l'apprentissage impliquent l'usage simultané de diverses modalités, notamment visuelle, auditive, tactile et kinesthétique, ainsi que d'autres modalités possibles. L'article analyse les affordances de l'apprentissage multisensoriel à travers le cadre de la sémiotique de la culture et de la recherche contemporaine en matière d'éducation, en outre, il examine les rapports entre la perception multisensorielle de l'environnement et la multimodalité représentationnelle dans l'apprentissage. La nature multimodale de la communication humaine est devenue explicite à l'époque de l'Internet et de média audiovisuels. Le développement de technologies numériques a aussi permis d'envisager la multiplicité de modalités représentationnelles dans l'apprentissage. Tandis que des pratiques de l'apprentissage multisensoriel apparaissent généralement dans des contextes vernaculaires, les récents développements dans le domaine de l'éducation et de la sémiotique de la culture offrent des moyens sans précédent pour supporter de telles pratiques dans le cadre de l'éducation scolaire et extrascolaire. En plus, les pratiques de l'apprentissage multisensoriel sont inhérentes au développement de nouvelles littératies nécessaires à la recherche de la signification dans l'environnement médiatique contemporain. La discussion théorique est suivie de l'analyse d'un exemple pratique, notamment de la plateforme d'apprentissage numérique Education on Screen ("L'éducation sur l'écran"). Cette plateforme a pour objectif de faciliter un dialogue significatif avec l'héritage culturel au moyen de l'apprentissage multimodal et multisensoriel. 


\section{Introduction}

The recent research in the field of education (Shams et Seitz, 2008; Kress, 2003) emphasised the necessity to develop multisensory learning practices to address the multisensory nature of learners' perception. This conceptual change was accompanied by a variety of studies, which aimed at 'the mapping of all representational and communicative resources available to teachers and learners' (Kress et al., 2001: xi). At the same time, another group of studies has been focused more on assessing pupils' 'informal learning strategies' (Scolari et al., 2018: 803) and incorporating those in fostering skills and competencies for learning via different forms of media. As a result, the Jenkins' argument that pupils 'learn better through different modes of communications and thus the lesson is most effective when conveyed through more than one mode of expression' (Jenkins, 2010) shaped the focus of educational research towards 'the multiplicity of modes of communication that are active in the classroom' (Kress et al., 2001: 1), emphasising its role in formation of meaning.

The need to develop multisensory learning practices originates not merely from the nature of human perception of the environment, but also from the way culture communicates its texts. Thus, a meaningful dialogue with the cultural heritage requires mastering multiple skills, including 'the creation, production, sharing and critical consumption of narrative content' in various media and modalities (Scolari et al., 2018: 803).

What remains less clear is what the most beneficial ways of approaching multisensory learning are in the context of contemporary culture, as well as what the role of the actively developing digital environment is in fostering multisensory learning and developing a meaningful dialogue with culture.

The paper offers a theoretical framework for integrating multisensory learning into formal education. Thus, the paper emphasises the value of multimodality of representation of educational material as a necessary component of multisensory learning. The article also focuses on identifying the role of a digital learning environment in fostering a meaningful dialogue with culture via multisensory learning practices.

The methodological approach combines the two main focuses. On the one hand, it incorporates the recent research in multisensory learning, educational and psychological studies in relation to multisensory perception in learning. On the other hand, the methodology of the paper relies on the ideas of the Tartu-Moscow Semiotic School, more specifically on the works of Yuri Lotman.

The practical section incorporates the methodology of multimodal analysis (Kress, 2010; Kress et al., 2014), according to which the cognitive processes of students' learning can be analyzed in the form of the signs of learning. In the words of Kress, '[t]he sign which the child has made gives us an insight into his 'stance' in the world, with respect to a specific entity or phenomenon' (Kress, 2010: 182). The analysis focuses on the following dimensions: students' selection and adaptation of elements from the lesson; introduction of elements not made available by the teachers; arrangement of these elements into texts and their 'design'; the representational modes used by students; the physical characteristics of the texts - their materiality (ibid.: 46-47). The last parameter is omitted, since all works share the same physical form (drawings and texts produced with felt-tip pens on paper).

The theoretical framework has formed the basis for Education on Screen (EoS), which is a digital platform for secondary school students that aims to enrich formal education through a deeper understanding of cultural processes. The project is developed by the Transmedia research group at the University of Tartu (Ojamaa et al., 2019) and examines the phenomenon of multisensory learning both on meta-level and object-level. Apart from acquiring theoretical tools for defining and analysing multisensory phenomena in culture, students gain hands-on experience in multisensory production. The paper presents the experience of the team in creating and testing digital tools for multisensory learning.

The data used in the analysis includes observational field notes, feedback surveys and multimodal artefacts created by students.

The analysis of the methodology of Education on Screen provides the necessary theoretical and practical framework for developing digital learning practices. Education on Screen established the methodology, which aims to foster multisensory learning and development of a meaningful dialogue with heterogeneous texts of contemporary culture. As a result, the research provides not merely scientific implications, but also a useful methodological account for educational practitioners.

The research question is addressed by analysing the role of multisensory learning in contemporary educational environments (part 2.1); its analysis via cultural semiotics framework (part 2.2.); and the study of the role of a digital environment in fostering multisensory learning (part 2.3). The practical part addresses the methodological analysis of the platform Education on Screen (part 3).

\section{Multisensory learning and multimodal representation}

\subsection{Multisensory learning}

Recent research in psychology (Shams et Seitz, 2008: 1), education studies (Scolari et al., 2018) and semiotics (Ojamaa et al., 2019) emphasised the significant role of the multiplicity of representation in the efficiency of learning. These 
observations argue the need to develop learning environments, which would incorporate the multisensory learning paradigm. Multisensory learning is understood as a learning practice, which incorporates various information channels belonging to different senses, such as visual, auditory, olfactory, etc. (Baines, 2008: 21).

Various analyses of educational methodologies (Kress et al., 2001) have illustrated the value of using the multiplicity of modalities in representation in learning, which helps students to become more involved in the learning process, and aims at overcoming 'the limited processing capabilities of each individual channel' (Shams et Seitz, 2008: 5). Another significant reason for the growing use of multisensory practices in education is the multimodal nature of everyday reality and cultural environment. In other words, our "meaning-making" ability often relies on the simulteanous use of multiple sensory channels. As a result, the educational value of multisensory learning originates from the output that 'it is likely that the human brain has evolved to develop, learn and operate optimally in multisensory environments' (Shams et Seitz, 2008: 1). This argument emphasises the value of incorporating the benefits of diverse informational channels involved in representation of learning material in the development of the educational environment.

\subsubsection{Multisensory learning and unisensory knowledge}

The recent research by Blomert and Froyen (2010) identified the significant role of multisensory learning even in acquiring such competences as reading, which is commonly regarded as a unisensory process. It can be assumed that this argument could be relevant for a diversity of learning practices, which are influenced by 'recent cultural inventions' (Blomert et Froyen, 2010: 196). This argument makes unisensory acquisition of a variety of skills and competences less essential in terms of onto- and phylogenesis. The outcomes of recent research (Shams et Seitz, 2008), which emphasise that 'our experience in the world involves constant multisensory stimulation' (ibid.: 1), require reevaluation of multisensory mediation in learning.

The research by Shams and Seitz (2008) highlighted the importance of multisensory practices in learning and memorising of unisensory information. The use of a coherent representation via different mediums allows multisensory codification of unisensory data (Shams et Seitz, 2008: 4). As a result, 'the learning involves alteration of connections between modalities or the formation or alteration of multisensory representations, and the later presentation of unisensory stimuli will activate a wider, multisensory, network of brain regions' (ibid.). Thus, according to Shams and Seitz (2008), an important benefit of multisensory learning is its use of 'dual coding', which 'reduces cognitive load because information from different modalities can be more easily chunked into short-term memory and used to build long term representations' (ibid.: 5). As a result, 'repetition of information with variations in different sign systems or media (e.g. oral, written, audiovisual, etc.) is a central technique of acquisition and preservation of knowledge' (Ojamaa et Torop, 2015: 62-63).

\subsubsection{Multisensory nature of informal learning}

An important evidence of the value of multisensory learning originates from informal learning practices, which 'play a key role in the modern education of our youths' (Black et al., 2015: 2) and participatory cultures (Scolari et al., 2018). Contemporary informal learning practices have evolved to 'new spaces like social media, websites, online communities, etc.' (Scolari et al., 2018: 803). It can be argued that informal learning practices are multimodal and multisensory by nature. This argument also reflects the recent outcomes of the research in multisensory learning (e.g. Shams et Seitz, 2008: 1), which emphasise that the natural environment, in which human brain is used to operate, essentially involves multisensory perception.

As a result, 'combining different media platforms in education enhances the outcome of learning' (Ojamaa et Torop, 2015: 63). In contrast, offering unisensory acquisition in a classroom, even for mediating initially unisensory information, would presuppose learning practices which are considered as 'unnatural settings and do not tap into multisensory learning mechanisms that have evolved to produce optimal behavior in the naturally multisensory environment' (Shams et Seitz, 2008: 1).

\subsubsection{Multisensory and multimodal learning}

It can be assumed, that an important role in the development of multisensory learning practices belongs to the growing use of new media (Kress, 2003) in education. The value of new media in multisensory learning originates from its effect on learning practices, as it made 'it easy to use a multiplicity of modes' (Kress, 2003: 5) in learning. The recent research in semiotics and media (Scolari et al., 2019) have provided a significant account for 'model[ing] the effective use of different media platforms in the classroom' (Scolari et al., 2019: 118; Jenkins, 2010). This made it possible to evaluate the benefits of incorporating 'multiple platforms of communication' (ibid.) in learning practices.

The analysis of multisensory learning cannot be cohesive enough without addressing the relations between multisensory perception and multimodal representation, in which the former relates to the abilities and sensorial opportunities of learners and the latter to the ones of the learning environment. In addition, while analysing the multimodal representation, we should refer to the relations between mode and modality, where 'mode refers to the code used to represent the material (i.e., verbal versus nonverbal) whereas modality refers to sense system used by which the learner 
receives the material (i.e., auditory versus visual)' (Moreno et Mayer, 2007: 310). While incorporating the diversity in the use 'of mode (say, writing) with medium (say, book)' (Kress, 2003: 5) in communicating learning material, multimodal representation aims to address the heterogeneity of learners' perception channels. As a result, the methodological approach of 'increasing prevalence of multimodal texts (texts-as-objects which use more than one mode of meaning-making) and multimodal communication' (Kress et al., 2001: 42) in learning attempts to imitate a more essential learning environment.

\subsubsection{Cultural environment}

The role of diverse media in mediation of learning material cannot be separated from the role of cultural environment in which meaning-making occurs. An ability of culture to communicate its main texts across heterogeneous media platforms (Jenkins, 2010) emphasises the role of multisensory learning in the meaning-making in contemporary culture. Moreover, cultural conventions guide our abilities of meaning-making and learning, when learning material is mediated simultaneously in various modes of representation. This argument originates from the role of congruence (Shams et Seitz, 2008: 2-4) in multisensory learning as 'low-level multisensory interactions are specific to congruent stimulus features' (ibid.: 3). As a result, learners' cultural background becomes an essential aspect of meaning-making via multimodal representation, as 'many multisensory congruences can only exist as a function of our experience' (ibid.: 4). The analysis of cultural processes makes it possible to identify the ways of incorporating the affordances of multisensory learning for developing meaning-making of cultural texts, as well as establishing a meaningful dialogue with culture.

\subsection{Cultural semiotics}

How can the semiotics of culture contribute to the conceptualisation of multisensory learning? The theoretical framework lying at the core of Education on Screen allows analyzing the principles of human expression and communication from the perspective of the universal cultural dynamics, as well as highlighting the multisensory aspects of any learning process.

\subsubsection{Cultural semiotic framework: basic notions}

The theoretical framework is based on ideas of the Tartu-Moscow Semiotic School, specifically the works of Yuri Lotman (for more detail see Ojamaa et al., 2019). Whereas linguistics focuses on the natural verbal languages (such as English, Estonian or any other), semiotics of culture takes into account the languages of culture - the systems of communication in various forms and modalities including visual art, music or cinema, etc. Various languages used in the society play the major role in the process of cultural self-description, or cultural autocommunication - constant repetition of meaningful information across the languages of culture (Lotman, 2000: 129). Cultural autocommunication is seen as the most universal feature of any culture, which fulfils both the mnemonic and preservational functions: 'repetition of information with variations in different sign systems or media (e.g. oral, written, audiovisual, etc.) is a central technique of acquisition and preservation of knowledge' (Ojamaa et Torop, 2015: 62-63). From the perspective of the semiotics of culture, the repetition of knowledge across different languages may be considered as an example of translation. In contrast to a common-sense understanding of translation as communication of meaning from one natural (verbal) language to another, the cultural semiotic definition is much more general and can be attributed to a wide range of processes, such as, for instance, the adaptation of a novel into a video game. Since full translatability between cultural languages is never possible, this makes such attempts inexact, unpredictable, and also creative. Yuri Lotman defines translation as 'an elementary act of thinking' (1990: 143): while merely reading any text, we already create its translation in the language of our consciousness. The semiotic notion of text also requires an explanation: in contrast to a commonly-accepted definition of text as a piece of writing, the text from the semiotic point of view is 'the primary element (basic unit) of culture' that can be produced in different cultural languages (Lotman et al., 1973: 4).

The more a text has been interpreted and mediated, the more deeply it grows into the culture: the most popular stories are being constantly retold in books, films, paintings, TV series, comic strips and fan art. According to Ojamaa and Torop, 'any text may exist in a series of possible forms and interpretations, none of which is the ultimate or ideal one' (2015: 64).

\subsubsection{Implicit and explicit multimodality}

Any act of human communication could be considered as multimodal, as it necessarily involves several modalities at once (see part 2.1.3). For instance, a lecture given in a classroom can be analyzed not only content-wise, but also from the perspective of movement, gestures, intonation and other non-verbal resources. Each of the modes plays a discrete role in a communicative act and 'provides specific potentials and limitations for communication' (Kress, 2004: 5).

Multimodality is implicitly present in seemingly monomodal texts, such as a written text without any illustrations (see part 2.1.1). As human perception of the world is multimodal, the brain tends to compensate for the missing modalities in 
the reading process (Fleckenstein, 1996). Verbal-linear and iconic-spatial languages of culture are regarded as complementary: the perception of a written narrative is inseparable from mental construction of images - visual, audible, even olfactory and tactile. Any artistic text not only exists at the intersection of the multiple languages of culture, but is also inseparable from its medium (so that the perception is affected by paratextual factors) and is intertextually connected to other texts (which can also be expressed in multiple modalities).

Digital technology has accelerated and amplified the processes of cultural autocommunication by intensifying various aspects of contemporary media (Hamilton et al., 2015: 19) and offering tools for integrating their means in a conceptual way (Ojamaa et al., 2019: 150). The implicit multimodality of literary text has now become explicit by means of transmedia storytelling, when 'transmedia story unfolds across multiple media platforms, with each new text making a distinctive and valuable contribution to the whole' (Jenkins, 2006: 97). While older pages 'embodied notions of authority and authorship', contemporary pages 'are designed on the basis of a quite different social relation of author, reader and meaning-making' (Kress, 2010: 37-38).

\subsection{Multisensory learning in the digital space}

\subsubsection{Educational aspects}

The digital environment allows integrating almost unlimited amounts of verbal, audiovisual, or other sensory information. Whereas the repetition of knowledge across multiple languages enriches the culture, it also implies that some aspects of the original meaning could be lost in translation. Multisensory learning can help students to gain different perspectives on the same object by exploring it in multiple forms; at the same time, it requires that the fragmented pieces of knowledge are integrated into a meaningful whole. The incompleteness of information is compensated with its stereoscopicity - 'the possibility of getting a completely different projection of the same reality, its translation into a completely different language' (Lotman, 1992: 45). Stereoscopicity can be seen as a key aspect of cultural autocommunication: the development of non-identical images of the text in the minds of different people makes communication more complex and at the same time enriches culture (ibid.).

Reading texts in the digital age requires that learners 'actively seek out content through a hunting and gathering process which leads them across multiple media platforms' (Jenkins, 2010). This allows to consider learning as a process of design, and the students - 'as authors of knowledge they want and need, authors of the kinds of texts that meet their social, personal and affective needs' (Kress, 2010: 145). While the multimodal design offers different points of entry into a text, it is the task of the reader to find and create a reading path: for instance, it is possible to get acquainted with the metatexts prior to reading the original text itself, or dwell on visual representations of the story instead of reading the words. In this case, the process of internalisation takes place as follows: '[...] interest shapes attention, which produces engagement leading to selection of elements from the message, leading to a framing of these elements, which leads to their transformation and transduction, which produces a new ('inner') sign' (ibid.: 42).

\subsubsection{Opportunities and limitations of the digital environment}

The integration of 'image, audio and video [...], animation and even virtual reality' (Peters, 2000: 4) in the simultaneous representation of learning material provides a new range of opportunities in fostering multisensory learning. One of the most significant opportunities in mediating learning material in a digital environment is 'the combination and integration of these presentation modes' (ibid.: 4). This allows learners to use the affordances of multiplicity of modes in the meaning-making of learning material.

Another significant opportunity of the digital environment in relation to multisensory learning is the development of new skills and literacies necessary for contemporary education. A cultural shift to a more diverse use of new media has shaped the understanding of skills and competencies which a learner acquires in terms of general education (Kress, 2003). As a result, 'literacy foregrounds the technological, cultural and historical specificity of particular media as used in particular times and places' (Livingstone, 2004: 3). Formal and especially informal education practices (Scolari et al., 2018) involve learners in the meaning-making through the multiplicity of texts of the digital space. This process requires educational methodologies to foster the development of media literacy, as 'the ability to access, analyze, evaluate and create messages in a variety of forms' (Livingstone, 2004: 3). It also requires the development of the diverse transliteracy landscape, which includes 'skills, knowledge, thinking, and acting, which enable fluid "movement across" in a way that is defined by situational, social, cultural, and technological contexts' (Sucovic, 2016: 8). This scope of abilities originates from the multimodality of the cultural environment, and thus the acquisition of it relies on the affordances of multisensory learning practices.

At the same time, we should argue that the use of digital media in learning possesses some specific limitations. These limitations relate to a diversity of modes, which are available for digital representation, focusing on the affordances and 'the dominance of the medium of the screen' (Kress, 2003: 1). It could be argued that a screen has been recently considered one of the most influential mediums of communication (ibid.). The methodological shift towards multimodality is frequently related to the mere affordances of the screen. However, according to the previous research, it can not be scientifically relevant to prioritise the screen in learning among the other mediums (and follow the invalid 
hypotheses of learning styles; Baines, 2008), as it would minimise the pedagogical effect of incorporating the multiplicity of mediums.

As a result, digital learning practices minimise the use of multiple senses and merely foster the use of digital sensoriality. On the one hand, these limitations do not allow learning practices to develop a holistic multisensory learning environment. Whereas, on the other hand, such limitations emphasise the need of incorporating the use of the screen into the vernacular learning space of a real classroom. This allows to develop a holistic learning environment, which is able to incorporate the affordance of the multiplicity of mediation in culture (see the next part).

\section{Education on Screen}

The theoretical framework of multimodality of cultural autocommunication and its relation to the multisensory nature of meaning-making processes can be practically illustrated with the analysis of the platform Education on Screen (EoS). The platform helps learners to establish a meaningful dialogue with significant cultural texts via their diverse representations in contemporary culture, while it incorporates a multiplicity of pedagogical tools, which aim to foster multisensory learning.

EoS includes three platforms based on popular Estonian literary texts and their cinematic adaptations: Literature on Screen (LoS), History on Screen (HoS), Identity on Screen (IoS). Each project offers a theoretical framework and materials for its practical implementation: excerpts from films and novels, examples of reception on social media, illustrations, analytical tasks and interactive assignments. All content is divided into bite-sized modules which allows building customised lesson plans for different purposes. The following parts summarise the results of testing that took place in Estonian secondary schools in the years 2017-2019. LoS was tested by over 200 students in 2017-2018; HoS was tested by over 100 students in 2018-2019; IoS was tested by a small focus group in 2019. The testing included students of 9-11 grades.

\subsection{Literature on Screen}

Literature on Screen (kirjandus.haridusekraanil.ee) is based on the Estonian best-selling novel Old Barney or November by Andrus Kivirähk (2000) and its foreign-Oscar-running cinematic adaptation November by Rainer Sarnet (2017). The novel, as well as the film, contains numerous references to Finno-Ugric folklore and different aspects of Estonian history.

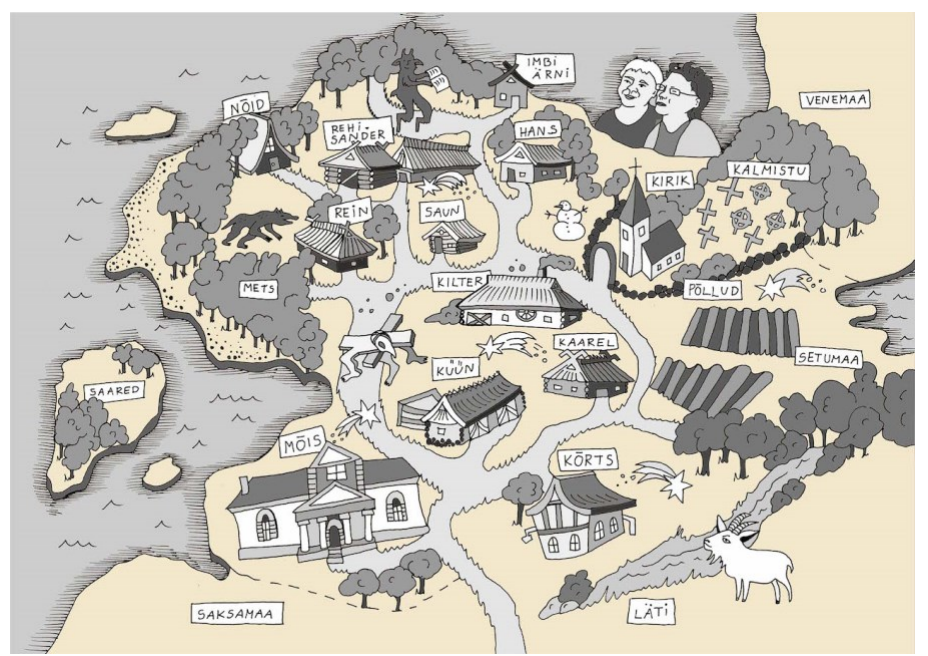

Figure 1. Map of the storyworld. Literature on Screen. Illustration by Katariin Mudist.

The platform includes a map of the storyworld and three theoretical sections. Students are encouraged to not only to compare the source text to its adaptation, but also to embrace the whole lifecycle of an adaptation and contribute their interpretations: write a script, choose a soundtrack, make a mood board, etc. The platform offers theoretical tools for understanding multisensory processes in culture as well as practical tasks.

\subsubsection{Exploring the implicit and explicit multimodality}

The first part of the given task encourages students to explore the implicit and explicit multimodality of the artistic text by comparing the original text to its prototexts, metatexts and intertexts. The prototext is defined as 'a text which serves 
as an object of inter-textual continuity' (Popovič, 1976: 226), or the first version of the story presented, whereas the 'metatext is a model of the prototext; the way in which two texts are linked' (ibid.). The intertextuality is understood from the perspective of Julia Kristeva, according to whom 'any text is constructed of a mosaic of quotations; any text is the absorption and transformation of another' (Kristeva, 1980: 66).



Figure 2. Prototexts and metatexts of Old Barney or November by Andrus Kivirähk. Literature on Screen. Illustration by Katariin Mudist.

At first, the notions are introduced in infographics: Estonian folklore and National Romanticism are seen as prototexts of the novel, while adaptations in different media - the opera, board game and film - are considered as its meta-texts. Secondly, students explore a photo gallery of Johannes Pääsuke's ethnographic photographs that have inspired the author of the film adaptation. Finally, students compare two videos both depicting processions of ghosts - a clip from Sarnet's November and its intertext - an excerpt from Akira Kurosawa's Dreams.

The tasks help to explore the multisensory aspects inherent to the existence of any artistic text. Students are introduced to the cultural context of the novel and film, which allows them to reveal hidden meanings of the texts. On the one hand, students concentrate on a specific feature of the original texts (for instance, the procession of ghosts); on the other hand, the given materials expand the artistic universe by establishing connections to other works of art.

The task aims to promote literacies belonging to the domain of narrative and aesthetic skills (Scolari et al., 2018: 805). Students are invited to compare different types of narrative and reflect on the connection between them. While doing so, they explore the modelling capacities of different media: learners see how the elements from one work of art penetrate other texts and analyse the translatability of these elements. Finally, students learn to juxtapose different levels of analysis and find balance between immanent and contextual analyses of text. However, the tasks are mostly reflective and do not require searching for information or creative production.

\subsubsection{Analysing the audience reception}

In order to analyse the place of an adaptation in culture, it is not enough to define its relation to a literary source. Both marketing materials and reception texts can be seen as a part of the transmedia universe of the novel and film. Each of these texts offers a new perspective on a source text, since their authors focus on various aspects of the original and choose different dominants. While exploring the mechanisms of marketing and readers' reception, students learn that the meaning of an artistic text keeps changing even after the author's work is over, due in no small part to the doings of participatory culture (Jenkins, 1992).

Firstly, students are asked to find all media platforms used by filmmakers for promotion and define the role of each one. As a warm-up exercise, learners analyse the poster and trailer of November (both available via LoS). Secondly, students focus on readers' reception by searching for user-generated content on social media, such as posts on Twitter, book reviews or amateur videos. In both tasks, we invite students to think how different platforms help to form the image of the text.

The tasks imply active participation of the students who have to deal with content management, evaluate the role of media platforms and use digital skills to find, describe and compare different texts. In the both tasks, learners have to process large datasets and filter out irrelevant information. Synthesising scarce messages into a coherent system requires skills of critical thinking and analysis. 


\subsubsection{Designing a character}

The most complex task on the platform requires that students analyse representations of a character in different media and create new versions. The character is a kratt, a treasure-bearer of Finno-Ugric mythology, featured both in the novel and film. We offer different types of materials that can be used as a source of inspiration: verbal descriptions of a $\mathrm{kratt}$ from the novel, a gallery of still shots from November, a gallery of versions in different media (book covers in different languages, photos of theatre performances, paintings, etc), and an interactive digital game that allows designing a $\mathrm{kratt}$ from household items.

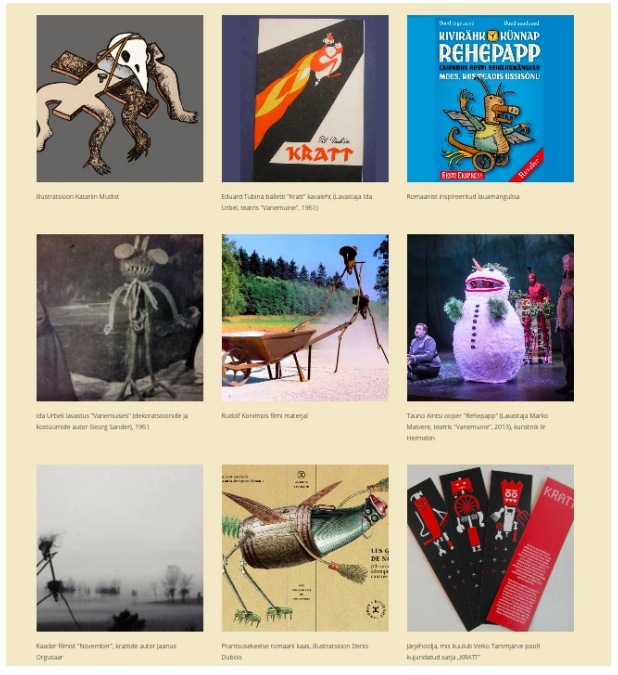

Figure 3. Representations of kratt in the Estonian cultural texts.

The task models processes of cultural autocommunication: students can follow the transformation of kratt's image and contribute to this process with their creative works. Visualisations produced by students become a part of the transmedia universe, which embodies the principle of performance, as identified by Jenkins (2010). While looking at the representations of a kratt in different media, students analyse how the novel and the film support and transform the tradition.

The task can serve as a final group project showcasing the skills and knowledge acquired by students: successful completion requires teamwork, critical thinking, analysis and production. It puts an artistic work into the context of the whole culture and allows students to learn more about folklore, history or art. Whereas the task appeared to be very complicated both in terms of technological solutions and students' work, it was also the most rewarding one.

\subsection{History on Screen}

History on Screen (ajalugu.haridusekraanil.ee/en/) is based on an autobiographical trilogy (Comrade Child and grownups 2008, Velvet and sawdust 2009, The touch of a woman's hand 2018) by an Estonian literary classic author Leelo Tungal and its adaptation The Little Comrade (2018) by Moonika Siimets. The novels describe a tragic time of Stalinist repressions through the eyes of a little girl, whose mother has been deported to Siberia. The platform includes three theoretical chapters and a map of the storyworld. HoS is focused on the transmediality of memory processes and aims to explore how the image of the past is formed. Rather than following the approach of academic history that values only official documents and facts, HoS encourages students to appreciate informal and multimodal sources, starting from oral stories to archive photos.

\subsubsection{Creating a memory-picture}

To start with, students investigate how novels, films, historical books, old photos and other texts intertwine in the historical consciousness of a person. The task consists of three parts: at first, students choose a story or a certain historical period and try to picture it in their imagination; secondly, they search for relevant images and put them together into a collage; thirdly, they analyse the result by paying attention to modes and sources they have used. The task is presented in a verbal form with a link to an online editor for making collages. We do not provide any ready-made content or links, so that the students can freely use any sources they prefer.

While the task does not mention the novel or the film, it is implicitly related to them. By investigating their memory processes, students can gain a better understanding of the similar processes taking place in the consciousness of writers 
and filmmakers. This activity can be associated with world building (Jenkins, 2010), since it involves mapping of the past in the form of a coherent system. The task invites students to immerse themselves in Soviet era, and, at the same time, produce something on their own.

Successful completion of the task requires the skills related to analysis, management and production. Learners explore the affordances of different media and analyse how stories, images, sounds, videos and physical sensations form a whole in their memory. In the final stage, they are asked to reflect on the dominant modes and sources present in their works.

\subsubsection{Visualising a scene}

The following task offers students to make visualisation of a scene based on the script of The Little Comrade. To create a historically correct picture of the Soviet 1950s, they are provided with a selection of archives and visual databases (digital collections of museums, photo archives, etc.). Students search for relevant materials and integrate them in a coherent collage: these can be images of clothes, interiors, urban spaces, consumer goods, etc. The important requirement is that the visualisation should bring out crucial visual details mentioned in the script. The task is described in a verbal form with some hyperlinks to archives. The collages are created in groups in a classroom or as homework.

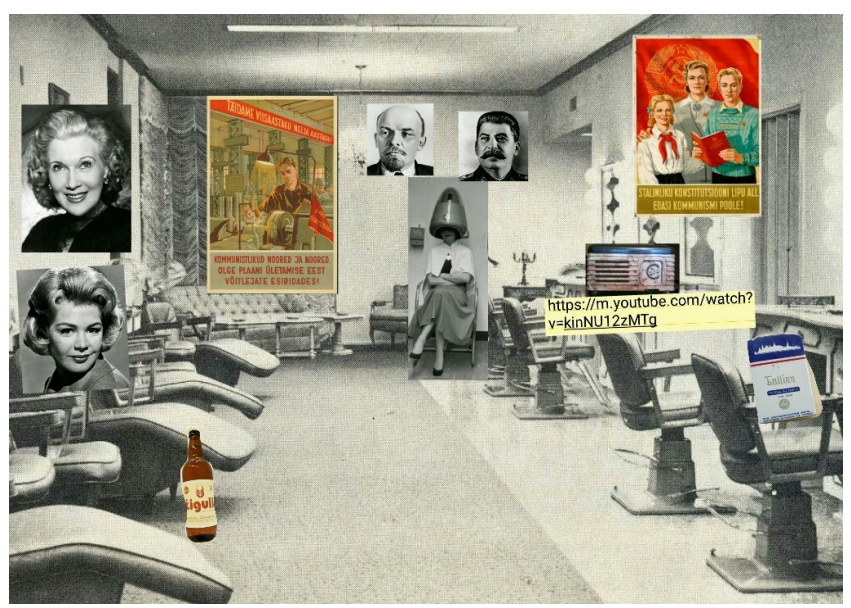

Figure 4. Visualisation of the scene from The Comrade Child. Student's work created for the workshop "Artistic text as a mediator of historical memory" (30.11.2017).

As in the previous case, the task implies both immersion and extraction: on the one hand, students explore digital representations of the Soviet era; on the other hand, they create new artefacts based on the found material. These activities help to enforce the spatial dimension of history, while mimicking the work of production designers. The images of objects and interiors can be seen as a part of the transmedia universe of the novel and film. While students are working with digital archives and databases, they can not only broaden their knowledge of the historical period, but also use this knowledge to better understand the text.

The task employs a wide range of transmedia skills related to social management, content management, media and technology, ideology, aesthetics, and production. Students are encouraged to convey the mood and atmosphere of a scene, which requires creative thinking. They need to not only find relevant pictures and integrate them into a coherent collage, but also make sure that all images are historically correct. This appeared to be a tricky requirement, as some students failed to select the elements critically and sometimes made amusing mistakes - for instance, accidentally used a photo of SS militant instead of KGB officer.

\subsubsection{Creating a book trailer}

As an additional task, students create a trailer for Leelo Tungal's trilogy with the help of open sources: collections of sounds, videos and images. At first, they analyze how to convey the message of the text by using a single sentence or a summary and secondly, create a script for the trailer. The final work needs to create appropriate emotions in viewers and be stylistically relevant. The task is presented in a verbal form, with a list of links to open sources.

While creating book trailers for Leelo Tungal's novels, students expand the transmedia universe of the text. The task may be both challenging and rewarding, as students need to find a new perspective that is not present in the official trailer of The Little Comrade. Moreover, learners have to create different trailers for each part of the trilogy and make sure that they are not repetitive. As in the previous task, students immerse into the transmedia universe of the text and simultaneously enrich it while providing new interpretations. 
The task helps students to focus on the modelling capacities of different media. Since trailers are generally short, groups need to find the most effective tools for conveying their message. The task requires many transmedia skills, including the ability to evaluate, compare and combine different media.

\subsection{Identity on Screen}

Identity on Screen (identiteet.haridusekraanil.ee/en/) focuses on the problem of identity and is based on the novel Truth and Justice by a major Estonian writer Anton Hansen Tammsaare and its screen adaptation by Tanel Toom. In contrast to the previous platforms, that mostly cover topics of human sciences, IoS aims to integrate different subjects from the fields of humanities as well as social and natural sciences. The platform does not have separate theoretical chapters, since all content is presented in the form of the map. Whereas EoS is not specifically focused on the problem of transmediality, this concept is implicitly present in almost all parts. The platform explores a different aspect of transmediality and focuses on how various texts are involved in building of cultural identity.

\subsubsection{Creating a script and a storyboard}

The part named Film Language deals with the concept of glocalization and discusses how global phenomena are reconceptualised by national cultures. This process is essentially transmedial, as it transcends the borders of media. The Truth and Justice film is seen as simultaneously belonging to Estonian national culture and following the principles of Hollywood cinema. For a practical assignment, students choose an excerpt from the novel and create a script and storyboard in a certain Hollywood genre. After that, they compare their work to a corresponding scene in the film and to other students' works. The task is presented in a verbal form, with a list of links to educational videos on Youtube explaining the features of Hollywood genres.

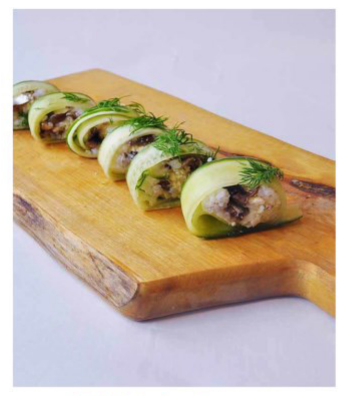

Sushi the Estonian way

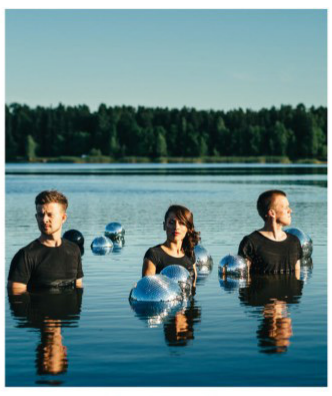

Trad.Attack!



Muhu keds

Figure 5. Examples of glocalization in Estonia. Identity on Screen.

The task encourages students to acquire a critical perspective on Truth and Justice and the film industry in general. While noticing features of Hollywood cinema in Truth and Justice, students learn to analyse the genre of an artistic work and juxtapose local and global contexts. While teams are not required to shoot an actual scene, they try to represent the peculiarities of different genres in a script and storyboard. This makes the task even more complex, since it may not be easy to follow the conventions of Hollywood cinema in unusual media. As in the previous task, it is necessary to choose the dominant that would connect the works to the original text.

The task requires skills related to the analysis and production of content. Students are asked to compare the original scene from the book to their versions and notice what has changed in the characters, mood of the scene, and overall meaning of the text. Also, they compare their works to corresponding scenes in Truth and Justice. In order to complete the task, students need to analyse the affordances of different genres and reflect on how discourse affects the meaning of the text.

\subsubsection{Shooting a video from an animal's perspective}

The part named Animals focuses on the relationships of Truth and Justice characters with animals and invites students to reflect on the perception of the environment by different animals. At first, students listen to a short lecture, in which the zoologist describes senses of seeing and hearing of horses, cows, dogs, and pigs. Learners note important features of an animal's perception: point of view, hearing, colours, etc. Secondly, students choose a scene from the novel depicting given species and create a script for it. Finally, teams shoot and edit videos by using mobile applications (a list of software is provided).

Even though the lecture does not mention the novel or the film, it highlights the ecological and ethical dimension of problems discussed in Truth and Justice. Students reflect on how the relationships between humans and other species 
have changed since the end of the 19th century. Retelling a story from the perspective of an animal is a popular artistic device that has been used by writers, filmmakers and other artists (for instance, see Kholstomer by Leo Tolstoy that adopts the perspective of a horse). The task allows acquiring a different perspective on the story, which corresponds to the principle of subjectivity - 'looking at the same events from multiple points of view' (Jenkins, 2010).

Since all necessary information is provided in the description, the task mainly requires skills of social management and production. Students need to find creative solutions for mimicking the vision and hearing of various animals: in order to do so, they can use filters (digital or analogue) and apply special effects during the editing. The task connects the artistic work to a physical environment and uses the fictional story as a starting point for exploring the natural world.

\section{Conclusion}

The experience of Education on Screen demonstrates how multisensory learning can be integrated into the system of school education. The tasks offered by EoS encourage students and teachers to step away from a logocentric and univocal understanding of cultural phenomena and embrace the versatility of cultural forms.

From the perspective of semiotics of culture, 'the dynamic processes of culture are constructed as a unique pendulum swing between a state of explosion and a state of organisation which is realised in gradual processes' (Lotman, 2009: 158). The rapid development of digital and multimodal practices can be seen as a moment of explosion - 'the place where a sharp increase in the informativity of the entire system takes place' (ibid.: 14). The latter is inevitably accompanied by the stage of gradual change, which, in this case, is exemplified not so much by the educational policies as by the grassroot movement of enthusiastic educators.

Whereas literary reading has traditionally required uninterrupted and lasting attention to a single subject, contemporary media environments increasingly favor the ability to multitask and switch between modes and media. Digital environment is associated with a certain type of reading that is based on fragments rather than on full-length texts; employs spatial rather than linear logic; juxtaposes different versions of the same text in various discourses and media. Reading on the Internet usually has a transmedial nature implying that readers 'actively navigate across various media platforms in order to gather the necessary materials' (Jenkins, 2010). Students navigate through transmedia universes of different texts and create their own versions and interpretations thus participating in the process of cultural autocommunication. This dialogue with cultural heritage requires mastering of transmedia skills that include creation, production and consumption of narrative content in different forms. Activities offered by EoS aim to promote key literacies, including those related to production, social and individual management, content management, media and technology, ideology and ethics, narrative and aesthetics. Instead of limiting themselves to immanent analysis of a literary text, learners deepen their knowledge by exploring transmedia universes. Since every artistic text models the real-life world, digging into the universes of The Old Barny, The Little Comrade or Truth and Justice can simultaneously mean immersion into actual history, geography or politics.

One of the most important outcomes of the approbation of EoS methodology is the ability of a digital platform to increase the benefits of multisensory learning for a variety of learning practices, more specifically for those school subjects, which are normally considered monomodal. The multimodal representation of learning material in EoS allows to increase the amount of information which is 'integrated across multiple sensory modalities' (Shams and Seitz, 2008: 1). The methodological focus on integrating learning on EoS with learners' vernacular informal learning practices also contributes to establishing a more essential learning environment, which relies on the affordances of multisensory learning.

The effectiveness of EoS as a learning method depends on motivation and expertise of teachers, as well as of students. Indeed, both development and implementation of such projects may be very energy-consuming. However, as has been shown by the conducted workshops, even untrained participants can come up with proposals for similar projects in less than an hour. While using the experience gained during testing, the team of EoS plans to continue working on current projects and develop new ones.

Digital learning platforms, such as EoS, can provide support for school teachers by offering the theoretical and practical framework for multisensory learning. At the same time, they support the transformation of the role of a teacher, who become 'knowledge facilitator' or 'cultural translator', serving as 'an interface between the educational institution (the classroom, the school) and the external media ecology where the students live and create' (Scolari, 2018: 15).

\section{References}

Baines Lawrence. (2008). A teacher's guide to multisensory learning: Improving literacy by engaging the senses, Virginia, USA: ASCD.

Bezemer Jeff, and Gunther Kress. (2008). Writing in multimodal texts: A social semiotic account of designs for learning. Written communication $25, \mathrm{n}^{\circ}$. 2, p. 166-195.

Blomert Leo, and Dries Froyen. (2010). Multi-sensory learning and learning to read. International journal of psychophysiology $77, \mathrm{n}^{\circ} .3$, p. 195-204.

Fleckenstein Kristie S. (1996). Images, words, and narrative epistemology. College English 58, no . 8, p. 914-933. 
Hamilton Mary, Rachel Heydon, Kathryn Hibbert, and Roz Stooke (éd.). (2015). Negotiating spaces for literacy learning: Multimodality and governmentality, London: Bloomsbury Publishing.

James Karin H., Sophia Vinci-Booher, and Felipe Munoz-Rubke. (2017). The impact of multimodal-multisensory learning on human performance and brain activation patterns. In Sharon Oviatt, Björn Schuller, Philip Cohen, Daniel Sonntag, Gerasimos Potamianos (éd.), The Handbook of Multimodal-Multisensor Interfaces Volume 1. Morgan \& Claypool. Publishers.

Jenkins Henry. (1992). Textual Poachers: Television Fans \& Participatory Culture. London and New York: Routledge.

Jenkins Henry. (2006). Convergence Culture: Where Old and New Media Collide. New York and London: New York University Press.

Jenkins Henry. (2010). Transmedia education: The seven principles revisited. Confessions of an Aca-Fan. http://henryjenkins.org/2010/06/transmedia_education_the_7_pri.html, accessed on 15/11/2020.

Kress Gunther R. (2003). Literacy in the new media age. Psychology Press.

Kress Gunther R. (2010). Multimodality: A Social Semiotic Approach to Contemporary Communication. Routledge: London.

Kress Gunther, Carey Jewitt, Jon Ogborn, and Charalampos Tsatsarelis. (2001). Multimodal teaching and learning: The rhetorics of the science classroom. London and New York: Continuum.

Kristeva, Julia. (1980) Desire in Language: A Semiotic Approach to Literature and Art. Leon S. Roudiez (éd.), T. Gora et al. (trans.). New York: Columbia University Press.

Livingstone Sonia. (2004). Media literacy and the challenge of new information and communication technologies. The communication review $7, \mathrm{n}^{\circ}$. 1, p. 3-14.

Lotman Yuri M. (1990). Universe of the Mind. A semiotic theory of culture. London: IB Taurus.

Lotman Yuri M. (1992). Fenomen kultury [The phenomenon of culture]. In: Lotman, Y. (éd.), Izbrannye statji v trekh tomakh. T.I Statji po semiotike i topologii kultury. Tallinn: Aleksandra, p. 34-45

Lotman Yuri M. (2000). Universe of the Mind: A Semiotic Theory of Culture. Bloomington: Indiana University Press.

Lotman Yuri M. (2009). Culture and Explosion. Berlin, New York: Mouton de Gruyter.

Lotman Juri M., Boris A. Uspenskij, Vjacheslav V. Ivanov, Vladimir N. Toporov, and Aleksandr M. Pjatigorskij. (1973). Theses on the semiotic study of cultures (as applied to Slavic texts). Structure of Texts and Semiotics of Culture. The Hague, Paris: Mouton, p. 1-28.

Murray Micah M., Antonia Thelen, Gregor Thut, Vincenzo Romei, Roberto Martuzzi, and Pawel J. Matusz. (2016). The multisensory function of the human primary visual cortex. Neuropsychologia 83, p. 161-169.

Ojamaa Maarja, Peeter Torop, Alexandr Fadeev, Alexandra Milyakina, Tatjana Pilipovec, and Merit Rickberg. (2019). Culture as education: From transmediality to transdisciplinary pedagogy. Sign Systems Studies 47, no. 1/2, p. 152-176.

Ojamaa Maarja, Peeter Torop. (2015). Transmediality of cultural autocommunication. International Journal of Cultural Studies 18, no. 1, p. 61-78.

Popovič Anton (1976). Aspects of Metatext. Canadian Review of Comparative Literature 3: 225-235.

Scolari Carlos A., Maria-José Masanet, Mar Guerrero-Pico, and María-José Establés. (2018). Transmedia literacy in the new media ecology: Teens' transmedia skills and informal learning strategies. El profesional de la información (EPI) 27, no. 4, p. 801-812.

Shams Ladan, and Aaron R. Seitz. (2008). Benefits of multisensory learning. Trends in cognitive sciences 12, no. 11, p. 411-417.

Sukovic Suzana. (2016). Transliteracy in complex information environments. Chandos Publishing. 